\title{
FUERO PENAL MILITAR: \\ UNA COMPARACIÓN INTERNACIONAL
}

Alfredo Rangel SuÁrez*

Las Fuerzas Militares de Colombia podrían ser las únicas que en la historia universal han soportado la abolición del fuero militar en medio de una confrontación armada. Rescatar ese fuero es una de las urgencias del momento, pues se ha convertido es un asunto crucial para nuestra seguridad nacional. La Fuerza Pública padece en la actualidad una situación absolutamente inconstitucional, pues, aun cuando nuestra Constitución Política en su Artículo 221 establece claramente que todos los delitos cometidos por militares en servicio activo y en desarrollo de sus funciones serán conocidos y juzgados por tribunales militares, sin embargo en la actualidad, todas las acusaciones de que son objeto los uniformados las conocen de oficio y en primera instancia los fiscales y los jueces. Esta jurisdicción ordinaria genera entre las tropas una inmensa e insuperable desconfianza pues, en muchos casos esos fiscales y jueces han demostrado que no tienen la imparcialidad, ni la objetividad, ni el conocimiento necesario para impartir justicia.

El efecto de esta inseguridad jurídica ha sido desastroso para la operatividad de las tropas que ha caído en forma vertical año tras año a partir del 2009, a tal punto que en el 2011 las Fuerzas Militares habían reducido el número de sus acciones ofensivas contra los grupos irregulares en un $80 \%$ con relación al 2003, a pesar de que en este mismo período se incrementó su pie de fuerza en $40 \%$, su movilidad aérea subió un $22 \%$, y su presupuesto se aumentó en un $61 \%$.

* Director del Centro de Seguridad y Democracia de la Universidad Sergio Arboleda. 
Continuando con esta tendencia descendente, en el primer trimestre de 2012 las acciones ofensivas de las Fuerzas Militares descendieron en un $52 \%$ en relación con el mismo período del 2011. Esta merma sostenida de la operatividad, en cuya raíz esta la inseguridad jurídica por falta de fuero militar, sin lugar a dudas ha sido aprovechada por la guerrilla para aumentar sus acciones violentas contra el Estado, contra la sociedad y contra la economía nacional en muchas regiones del país.

En consecuencia, restablecer plenamente el fuero militar no es simplemente un asunto de interés académico o que solo incumba a los juristas. Es un tema de interés nacional porque su ausencia está afectando de manera grave la seguridad nacional.

Dentro del complejo tema de la justicia penal militar sobresale en primer lugar un asunto básico y definitivo: cuál es el alcance de su jurisdicción, es decir, cuáles son los delitos que conocen, investigan y juzgan los fiscales y jueces militares, su ratione materiae. Y este es precisamente el punto que diferencia el artículo que sobre el fuero militar fue introducido en el proyecto de reforma a la justicia, del proyecto de ley que sobre el mismo tema se tramita en el Congreso. Así, el mencionado artículo le otorga un amplio alcance al fuero militar al presumir que todas las acciones operacionales de las Fuerzas Militares son legales y hacen parte del servicio, razón por la cual los presuntos delitos cometidos en el curso de dichas operaciones militares deben ser conocidos y juzgados en primera instancia por fiscales y jueces militares. En contraste, el proyecto de ley le otorga un alcance muy limitado al fuero militar y establece unas engorrosas Comisiones conformadas por miembros de las dos jurisdicciones, la civil y la militar, para determinar, en cada caso que se presente una reclamación, a cuál de las dos pertenece el proceso.

No existe a nivel internacional una fórmula única para determinar el alcance que debe tener el fuero militar. Sin embargo, en la gran mayoría de los países se concibe un fuero militar muy amplio cuando se trata de situaciones de guerra de conflicto interno o de estados de excepción. Más restringido en algunos países cuando se trata de tiempos de paz o de normalidad. Pero en todos ellos el fuero militar no es un privilegio para los combatientes del Estado, sino una garantía necesaria que todas las democracias le otorgan a sus soldados, ciudadanos que ponen en riesgo mortal sus vidas para proteger la seguridad de la nación entera. 
Con base en el libro de Federico Andreu-Guzmán ${ }^{1}$, presentamos a continuación la situación del fuero militar en algunos países de Europa y América, en lo que tiene que ver con el alcance que en cada uno de ellos se le otorga a la jurisdicción penal militar. Para los casos específicos de Francia e Italia citaremos un reciente documento de EDUARDO MACKENZIE ${ }^{2}$.

En Argentina, durante los tiempos de paz, los tribunales militares conocen los delitos y faltas esencialmente militares, o sea, las que "pueden afectar la existencia de la institución militar" y que "exclusivamente las leyes militares prevén y sancionan". En tiempos de guerra, juzgan los delitos que son cometidos por militares en actos del servicio militar, por órdenes de los superiores militares o por requerimientos de las autoridades civiles. El Código Penal Militar conoce una muy amplia gama de delitos entre los que se encuentran: delitos contra el orden constitucional; contra la lealtad a la Nación; delitos típicamente militares; delitos comunes militarizados (prevaricato, cohecho, defraudaciones, entre otros); y delitos comunes (hasta hurto y robo) cometidos con ocasión del servicio, definiendo este como "todo el que se refiere o tiene relación con las funciones específicas que a cada militar corresponden, por el hecho de pertenecer a las Fuerzas Armadas", en particular los ejecutados en funciones de combate, de seguridad, de manejo de material, de instrucción y de formación. En tiempos de guerra el Código militar establece procedimientos extraordinarios, con características de juicio sumario.

En Austria no hay jurisdicción militar en tiempos de paz. En tiempos de guerra los tribunales militares conocen los delitos que el Código Penal Militar tipifica como "delitos profesionales" de las Fuerzas Armadas, delitos típicamente militares y algunos delitos comunes militarizados.

\footnotetext{
${ }^{1}$ Andreu-Guzmán, Federico: Fuero Militar y Derecho Internacional. Los tribunales militares y las graves violaciones a los derechos humanos. Bogotá, Comisión Colombiana de juristas- Comisión Internacional de Juristas, 2003. [También en línea, Disponible en: http://www.coljuristas.org/documentos/libros_e_ informes/fuero_militar_y_derecho_internacional.pdf. Agregado del Director]. ${ }^{2}$ Cfr. Mackenzie, Eduardo: "Colombia: La Justicia Militar, el ejemplo europeo" en HACER Latin American News, seis de abril de 2012. [En línea. Disponible en: http://www.hacer.org/latam/?p=14708. Agregado del Director]. Este documento lo hace el autor con base en el estudio del diputado francés Alain Marty que se encuentra en: http://www.assemblee-nationale.fr/13/pdf/ rapports/r3530.pdf
} 
En Chile el ámbito de la jurisdicción militar también diferencia tiempos de paz y tiempos de guerra. En este último los procesos de investigación son breves y sumarios, tanto que no pueden prolongarse más de 48 horas. El Código Militar abarca una amplia gama de delitos que van desde los típicamente militares hasta los delitos comunes cometidos en el ejercicio del servicio, entendido este como "todo aquel o tenga relación con las funciones que a cada militar corresponde por el hecho de pertenecer a las instituciones armadas", lo cual permite que, incluso, los jueces militares conozcan de los casos de violaciones a los Derechos Humanos realizadas por los uniformados.

En Canadá, aunque la justicia militar procesa solo las infracciones de servicio, delitos militares y faltas disciplinarias atribuidas a miembros de las Fuerzas Militares, se considera una infracción de servicio todo acto u omisión calificada como infracción por el código penal ordinario. Pero, cuando un asesinato o un secuestro son cometidos en Canadá, los juzgan jueces civiles; si ocurren fuera del país los juzgan jueces militares. No obstante, delitos como el asalto sexual, si se cometen dentro del país, son juzgados por la justicia penal militar.

En Ecuador, la jurisdicción de la justicia penal militar es muy amplia. Incluye no solo los delitos militares, sino los delitos cometidos por militares bajo la figura de actos del servicio. El Código Penal de la Policía Civil Nacional es también muy amplio: incluye delitos militares, contra el derecho internacional, policiales, contra los derechos políticos y las garantías constitucionales, homicidio, lesiones personales y delitos sexuales. En consecuencia, las violaciones a los Derechos Humanos son de competencia de los tribunales policiales.

En España, en tiempos de paz, además de los delitos típicamente militares, la jurisdicción militar conoce un amplio espectro de delitos: delitos comunes militarizados, o sea, cuando la ley militar tiene un mayor castigo; delitos que atentan tanto contra bienes jurídicos comunes como militares, siendo esto último prevalente; y delitos comunes militarizados, esto es, que no tienen relación con lo militar, pero están incorporados al Código Penal Militar. Durante el Estado de Sitio la jurisdicción militar puede ser extendida en la declaratoria del mismo a delitos a delitos tipificados en la ley penal ordinaria. En tiempos de guerra la jurisdicción se amplía aún más, además de los de tiempos de paz, a los de la legislación penal común cuyo conocimiento le atribuyan el Gobierno o las leyes; los tipificados por las leyes españolas, cometidos por militares en tierra 
extranjera; los cometidos por prisioneros de guerra; los delitos del código ordinario cometidos por civiles y que se convierten en delitos militares.

En Estados Unidos la justicia penal militar tiene una amplia cobertura, además de los delitos típicamente militares. Por ejemplo, los allí llamados "delitos convencionales" que se encuentran en los códigos civiles: asesinato, ultraje, asalto, sodomía, extorsión, incendio criminal, uso de estupefacientes, etc. También, están los delitos del Artículo General 134 del Código Penal Militar que declara criminales los actos contra el orden y la disciplina de las Fuerzas Militares, o que las desacredita. O delitos contra la aplicación de la Ley: escape de prisión, negarse a testificar, falsos testimonios, etc.

En Francia, "en tiempo de paz, toda infracción o delito penal cometido por un militar, o contra un militar, es tratado por el tribunal especializado en materia militar del tribunal de grande instancia designado por la ley. El código aplicado es el código de procedimiento penal, pero el militar tiene otras garantías adicionales importantes que preservan su derecho a la defensa: la acción pública sólo puede ser pedida por el Procurador de la República, pero únicamente si existe una denuncia previa de la infracción y ésta emana de una autoridad militar".

Adicionalmente, ".... ningún particular puede denunciar a un militar y pedir que se lo juzgue. Para evitar que una simple denuncia (justificada o de mala fe) rompa la cadena de mando, el pedido debe venir de una autoridad militar y, si la acusación es seria, el Procurador de la República la estudia antes de ordenar la acción pública. La confidencialidad de ciertas informaciones puede justificar la ausencia del jurado popular en el juzgamiento del militar. Es posible allanar lugares militares pero respetando ciertas reglas. Los militares deben ser detenidos en locales separados de los civiles".

De otra parte, en tiempos de paz y fuera de Francia "toda infracción o delito penal cometido por un militar, o contra un militar, es tratado por el tribunal de las fuerzas militares de París, sobre todo si la infracción fue cometida en un país ligado a Francia por acuerdos de defensa. El tribunal militar francés en Baden Baden se ocupa de las infracciones cometidas por las tropas francesas estacionadas en Alemania".

Finalmente, "en tiempo de guerra las medidas de excepción se justifican. Los poderes del ministerio francés de Justicia pasan al ministerio de Defensa. Se instauran tribunales militares dentro y fuera del territorio nacional. Esos tribunales serán presididos por un magistrado judicial 
asistido por cuatro jueces militares.Dentro de Francia, el Alto Tribunal de las Fuerzas Armadas es competente para juzgar a los altos mandos. Toda decisión de justicia debe ser motivada por escrito. Toda decisión de primera instancia puede ser apelada. El Parlamento debe autorizar la declaratoria de guerra. El gobierno, en situaciones de estado de sitio, de estado de urgencia, de movilización o de advertencia, puede tomar decisiones respecto de la justicia militar".

En Italia, "en tiempo de paz, los tribunales militares conocen los delitos militares cometidos por los miembros de las fuerzas militares. En cambio, no existe código de procedimiento penal militar, pues el código de procedimiento penal (de derecho común) es el que se aplica. En tiempos de guerra, los tribunales militares ordinarios son remplazados por tribunales militares de guerra con extensas competencias. Los magistrados militares tienen las mismas garantías de independencia que los magistrados ordinarios".

En Perú la jurisdicción militar abarca también un amplio espectro de delitos que incluye los delitos militares, los delitos militarizados, y delitos comunes en los que estén involucrados militares o policías como víctimas o como victimarios. El Código Penal Militar concibe de manera muy amplia el "delito de función", lo que ha permitido que incluso violaciones a los derechos humanos se incluyan en $\mathrm{su}$ jurisdicción bajo las figuras de "abuso de autoridad", "uso innecesario de violencia" o "privación ilegal de la libertad".

En Gran Bretaña, las infracciones al derecho común son conocidas por tribunales ordinarios, y las infracciones militares por la justicia militar. Sin embargo, por lo general las infracciones al derecho común cuando las comete un militar, son consideradas por los jueces como delitos militares y los casos son remitidos a la justicia castrense.

En Suiza el sistema penal militar distingue entre tiempos de paz y tiempos de guerra. En tiempos de paz, los tribunales militares juzgan a los militares por delitos cometidos en servicio o fuera del servicio, pero en el marco de sus deberes militares. El Código Penal Militar incluye un gran número de delitos, tanto los típicamente militares, como las violaciones al derecho de gentes. Pero también incluye muchos de derecho común: homicidio, secuestro, violación sexual, estafa, delitos contra la administración de justicia y delitos contra el patrimonio. La justicia penal militar también juzga a empleados, funcionarios y obreros civiles de las Fuerzas Militares por actos contra la defensa nacional. En tiempos de guerra la jurisdicción se amplía a civiles que cometen traición, espionaje, o ataques contra bienes militares. 
En Venezuela la justicia militar juzga los delitos militares y los delitos comunes cometidos por militares en unidades militares, en funciones militares, en actos de servicio, en comisiones o con ocasión de ellas. También los delitos conexos cuando el equivalente militar tenga una pena igual o mayor que el delito común. Los delitos conexos son los cometidos por dos o más personas, juntos o concertados, para perpetrar delitos o procurar su impunidad. Como detalle relevante, el Código venezolano tiene un Capítulo titulado "Delitos contra las Personas y las Propiedades" que tipifica delitos comunes ejecutados por militares que "... en actos del servicio o en el desempeño de una comisión relativa a él, hicieran innecesario uso de armas o de otra violencia contra cualquier persona".

Como se puede verificar, en todos los países examinados hay un alcance muy amplio de la justicia penal militar que solo se reduce en algunos países en tiempos de paz. Pero la gran conclusión es que en ningún país se restringe el fuero militar en tiempo de conflicto o de guerra. Esto evidencia un marcado contraste con la suerte que ha tenido el fuero militar en nuestro país desde hace casi dos décadas.

En efecto, los gobiernos han reconocido con sus decisiones políticas, sus medidas administrativas, sus estrategias y operaciones militares y sus iniciativas legales, la existencia de una amenaza armada contra el Estado y contra la sociedad, o de un conflicto armado interno, lo cual, obviamente, jamás ha significado otorgarle ningún tipo de legitimidad a los grupos guerrilleros. Sin embargo, distintas decisiones de los poderes públicos han ido recortando progresivamente el alcance del fuero militar para unas Fuerzas Militares que combaten día a día en una confrontación armada que les ocasiona miles de muertos y heridos. Se incrementa con toda razón y fundamento el presupuesto en defensa y seguridad para afrontar con éxito a los enemigos del Estado pero se restringe en forma absurda la garantía jurídica que es el fuero militar para nuestras Fuerzas Militares. Se les otorga a los soldados del Estado más recursos y se les rodea de apoyo público y de legitimidad, pero se reduce su certidumbre jurídica. Se les otorga apoyo material y político pero se les afecta la moral con la inseguridad jurídica por falta de fuero militar.

En conclusión, teniendo en cuenta la precaria situación actual del fuero militar en nuestro país y estableciendo una comparación con su vigencia en los países democráticos del mundo, creemos que en lo que respecta al alcance del fuero penal militar en Colombia, 
es necesario retornar sin esguinces ni exclusiones a lo establecido en el Artículo 221 de nuestra Constitución Política. Por razones de seguridad nacional es conveniente devolverle la seguridad jurídica a nuestra Fuerza Pública estableciendo que los delitos de que fueren acusados sus miembros en el ejercicio de sus funciones deben ser conocidos en primera instancia por los tribunales militares, al tiempo que se debe acometer sin tardanza la tarea de modernizar y hacer más eficiente la Justicia Penal Militar. Y ante el temor de ser objeto de señalamientos en el exterior, debemos reivindicar que esta decisión también es un acto de soberanía nacional: se trata simplemente de equiparar el fuero de nuestras tropas al que existe en los países democráticos del mundo. 